Discussion Paper No. 1004

\title{
GROUP SIZE AND CONFORMITY IN CHARITABLE GIVING: \\ EVIDENCE FROM A DONATION-BASED CROWDFUNDING PLATFORM IN JAPAN
}

\author{
Shusaku Sasaki
}

May 2017

The Institute of Social and Economic Research

Osaka University

6-1 Mihogaoka, Ibaraki, Osaka 567-0047, Japan 


\title{
Group size and conformity in charitable giving: Evidence from a donation-based crowdfunding platform in Japan
}

\author{
Shusaku Sasaki ${ }^{* \dagger}$
}

May $22^{\text {nd }}, 2017$

\begin{abstract}
This study examines relationships between the size of the majority and donor conformity by empirically investigating the impacts of multiple earlier donations on the amount that a subsequent donor contributes to JapanGiving, a donation-based crowdfunding platform. The platform's webpage displays the amounts of the preceding five donations in chronological order. Using data for 9,989 donations and exploring the model propounded by Smith et al. (2015), we construct variables to explain information a donor sees on the webpage. The main variables are the modal amount among the preceding five donations and their appearance along the sequence. Dynamic panel analyses suggest that when the two most recent donations are identical, a subsequent donor is likely to match the immediately preceding donation. The likelihood further increases when the number of the most recent continuous modal donations increases. We discuss that our findings connect
\end{abstract}

\footnotetext{
* Corresponding Author: Faculty of Economics, Keio University, Tokyo

E-mail: ssasaki.econ@gmail.com, Postal Address: 2-15-45 Mita, Minato-ku, Tokyo 108-8345, Japan

$\dagger$ This paper is a direct descendant of my two un-published working papers (Sasaki, 2014, 2015).

I thank the Japan Society for the Promotion of Science for financial support (Grant Number 14J04581). This research would not have been possible without support from JapanGiving. I thank its founders, Daigo Sato and Takuya Kajikawa. I thank Fumio Ohtake, Sarah Smith, Richard Steinberg, Mark Ottoni-Wilhelm, Sera Linardi, Rene Bekkers, Brenda Gainer, Atta A. Ceesay, Takanori Ida, Takahiro Hoshino, Katsunori Yamada, Miki Kohara, Yoshiaki Nomura, Naoto Yamauchi, and Ryo Okui for discussions, comments, and encouragement. I also thank participants at the 8th ISTR Asia Pacific Regional Conference 2013, ARNOVA's 42nd Annual Conference 2013, ABEF's 7th Annual Conference 2013, the Japanese Economic Association Fall Meeting 2014, the 9th Applied Econometrics Conference 2014, the Second SPI Annual Conference 2014 and ABEF's 8th Annual Conference 2014 as well as seminar participants at Osaka University and the University of Chicago (Science of Philanthropy Initiative webinar).

This paper is awarded "Emerging Scholars Award" at ARNOVA (Association for Research on Nonprofit Organizations and Voluntary Action) 42nd Annual Conference and "Encouragement Award" at ABEF (Association of Behavioral Economics and Finance) 8th Annual Conference 2014. All errors in this paper are my own responsibility.
} 
economic studies of charity and social psychology studies of conformity and could aid effective fundraising by charities.

Keywords: Charitable giving, Conformity, Fundraising management, Crowdfunding, Natural experiment, Online dataset

JEL Classification Number: D64, H41, C99 


\section{Introduction}

A charitable donor is influenced by other donors, and an influenced donor conforms to the others' contributions. Economists have revealed the existence of donor conformity. Field experiments investigate the impact of disclosures of other donors' contributions (Frey and Meier, 2004; Alpizar et al., 2008; Shang and Croson, 2009). For example, Shang and Croson (2009) randomly inform potential donors regarding another's donation, finding significant differences in average donations between informed and uninformed groups. In doing so, they demonstrate that donor conformity exists.

In practices, it is suggested that charities provide information about previous donations in soliciting new donations (The Behavioral Insights Team, 2013; Hardwick, 2014; Prior, 2014). We actually find the information on their solicitation letters, brochures, homepages, etc.

Then, when is a charitable donor more likely to conform to others' contributions? These issues in donor conformity remain a subject of debate and analysis. Answering these questions can further aid fundraising activities by charities. If we can reveal a secret that aids in strengthening a conformity effect, it could enable charities to collect donations more effectively and achieve fundraising targets at a faster pace.

One method ${ }^{1}$ of investigation involves providing potential donors with information regarding multiple donors associated with similar donation amounts. Social psychology studies report that individual conformity is strengthened when a large number of people behave in a similar way (Asch, 1951; Asch, 1955). ${ }^{2}$ In other words, when an individual imitates the choice that another individual has selected, a subsequent individual will likely match their choice. Furthermore, the likelihood increases with the number of the others who have selected the similar choice. If that is the case with charitable giving, providing information regarding multiple donors could influence potential donors more strongly if and when more of the multiple donors have donated the same amount as compared with other times when they may not donate the same amount in such high numbers. That is,

\footnotetext{
${ }^{1}$ Previous studies have explored the issues in other ways. Shang, Reed, and Croson (2008) found that donor conformity depends on similarities between donors; their findings indicate that when donors obtain information about another donor of the same gender, they are more likely to be influenced by the other donor. Croson and Shang (2013) find that donor conformity depends on the contribution level of the other donor. Their findings indicate that when donors see another's extremely high contribution, they are less likely to be influenced by it. Jones and Linardi (2014) and other literature find that donor conformity depends on the visibility of their contribution. That is, donors are more likely to be influenced by other donors when their own contribution is visible.

2 Extensive studies in social psychology have established a positive relationship between individual conformity and the size of the majority. See some earlier reviews for details (Tanford and Penrod, 1984; Bond, 2005).
} 
the subsequent donors' contribution could mirror the majority contributions of multiple donors.

We examine relationships between the size of the majority and donor conformity, by empirically investigating the effects of informing potential donors regarding the monetary contributions that multiple donors have already made to a crowdfunding platform in Japan. Our analyses employs the following data and model. First, our analysis uses data from 9,989 actual donations made through the website of JapanGiving. A unique feature of JapanGiving is that its fundraising campaign webpage displays the monetary amount of each individual preexisting donation in chronological order. Potential donors can see the five most recent individual donations and combinations of previous donations that are a result of the potential donors accessing the page at different times. Second, our empirical model uses variables to explain representative combinations of previous donations. The main variables are the modal amount among the five most recent donations and their appearance along the sequence. Subjecting the data to inferential analyses, we find the combination that most increases the likelihood of a new donor matching the modal norm established by previous donations.

Our data, model, and empirical strategy are based on those propounded by Smith, Windmeijer, and Wright (2015). They use a large sample of data from JustGiving and Virgin Money Giving in the UK, the webpages of which chronologically display the amount of each previous individual donation. Their analysis shows that a new donation amount responds to large donations and small donations among previous donations, changes in their modal amount, and the mean amount of previous donations. Their main finding is that a $£ 10$ rise in the arithmetic mean amount of all previous donations increases a new donation amount by $£ 2.5$. Our study adds to the literature by examining the significance of the number of people making donations of a similar size in terms of the likelihood of people following previous donations.

Our models include lagged dependent variables as independent variables. This causes a downward bias in fixed effects estimates (Nickell, 1981). We use a dynamic panel modelling approach to exclude the bias. In addition, our main analyses needs to assume that when donors visit the platform and its fundraising campaign webpage, and make their donation there is subject to random factors. The preliminary analysis corroborates this assumption, by confirming that the distribution of donated amounts on a webpage is stationary throughout the campaign. This result indicates that donations are plausibly homogeneous within each webpage. We further introduce our model specification and identification strategy in Section 4. 
Several findings emerge from our empirical analyses. The major finding is that when the two most recent donations are identical, a subsequent donor is likely to match the immediately preceding donation. In other words, when a previous donor imitates the amount that another previous donor have made, a subsequent donor will likely match their amount. Furthermore, we find that the likelihood increases when the number of the most recent continuous modal donations increases. These results support the notion that donor conformity is strengthened when a greater proportion of other donors give a similar amount as compared with a situation in which they do not.

One further analysis shows that the effects of continuous modal donations are observed more strongly in lower monetary ranges. This finding indicates that knowing previous modal donations in lower ranges could stick subsequent donors to the ranges. Another further analysis shows that information on continuous modal donations does not influence the emergence of a new donor on a webpage or the donation made by them. This finding addresses the concern regarding different cohorts of donors arriving at a webpage accordingly with the combinations of amounts of multiple donations.

To our knowledge, this study is the first to determine when a charitable donor is more likely to conform to the others' contributions in an environment that reveals the monetary contributions of previous donors. Our findings connect economic studies of charity and social psychology studies of conformity. Furthermore, our findings can assist charitable fundraising by suggesting that charities alter the presented donation amounts accordingly to achieve their fundraising targets at a faster pace.

This paper is organized as follows. Section 2 discusses previous studies. Section 3 introduces JapanGiving and the data recorded on its website. Section 4 explains econometric strategies. Section 5 presents the principal estimation results, and Section 6 provides further analysis of the estimated results. Section 7 discusses the study's implications and limitations and the scope of future research. 


\section{Literature review}

We apply findings from psychological studies of conformity to the economic analysis of charitable giving. In social psychology, Asch's $(1951,1955)$ conformity experiments have been replicated by an extensive literature of laboratory experiments. Their common finding is that people are more likely to select the option that more of others have selected. For example, Gerard et al. (1968) reported that people's conformity rises when the size of the majority widens from two to seven people. ${ }^{3}$ Although most results have been found in laboratories, a recent few studies start to complement these conformity experiments, by using more natural observations and assessing the role of conformity in everyday situations (Claidière et al., 2012; Claidière et al., 2014).

To conduct a similar investigation into real charitable giving, researchers would need to inform potential donors regarding combinations of multiple donations. Employing a field-experiment approach for the analysis would require a large number of treatment groups in natural settings; therefore, few relevant studies of charitable contributions have been undertaken. Martin and Randal (2008) use a see-through donation box in an art gallery to investigate how compositions of visible bills and coins influence new donations. However, they did not track and record each individual donation and so did not investigate how each donor reacted to the stimulus. Second, in a laboratory experiment, Samek and Sheremeta (2014) analyze the effects of recognizing only the largest or smallest among multiple donations and the effect of recognizing all multiple donations. However, it remains unclear how other combinations affect new donations.

How can we measure the effects of displaying various patterns of information? The marketing literature suggests that a website is ideal for such an investigation (Blake et al., 2014; Johnson et al., 2014; Lewis and Reiley, 2014), because the Internet lets researchers provide a website's visitors with extensive information. Furthermore, researchers can track and record detailed data on visitors, such as when they visited, what information they saw, and which activity they undertook. Researchers use the information to compute the effects of treatments' information on a visitor's activity. However, treatment information might not be randomly assigned to visitors. It must be confirmed empirically from data that visitors are sufficiently homogeneous for treatment identification.

The economics of conformity and peer pressure in charitable giving contexts has been explored using data recorded on JustGiving and Virgin Money Giving, which, as

\footnotetext{
${ }^{3}$ The form of the relationship between individual conformity and the size of the majority varies among studies even though most report a positive relationship. Gerard et al. (1968) established a linear relationship between the two variables; Rosenberg (1961) reported a curvilinear relationship.
} 
mentioned, chronologically display the monetary amount of each previous individual donation. Bøg et al. (2012) use a small sample of cross-section data, finding a systematic positive correlation between contributions in the early stage of a fundraising campaign and those in its later stage. Smith, Windmeijer, and Wright (2015) extend the literature by using a dynamic panel modelling approach on a large sample of micro panel data. The authors offer empirical evidence supporting the assumption that the timing of a donor making their donation is subject to random factors, and show that a donation responds to both large and small donations among previous donations, changes in their modal amount, and the mean amount of previous donations. They establish positive causality running from previous to new donations. Their study is the first to purely investigate horizontal interactions in charitable contributions (door-to-door fundraising).

We further add to the literature by using a sample of micro panel data recorded on JapanGiving. We lay importance on the number of people making donations of a similar size in terms of the likelihood of people following previous donations. In our estimation, the major variables are the modal amount among previous donations and their appearance along the sequence. We investigate whether a new donor will be more likely to contribute to the modal amount if and when more donors give identical amounts. 


\section{Setting}

\subsection{Website of JapanGiving}

JapanGiving is a donation-based crowdfunding platform, or an online fundraising intermediary that connects nonprofit organizations (NPOs) and fundraisers with potential donors. JapanGiving is the sibling of JustGiving in the UK, ${ }^{4}$ the world's largest fundraising platform. Between its public launch in March 2010 and December 2014, JapanGiving attracted 111,700 donations and facilitated $¥ 121.4$ million (US\$1.521 million at the 2011 exchange rate $)^{5}$ in contributions.

NPOs and fundraisers register with JapanGiving and create fundraising webpages for their causes. NPOs and fundraisers first solicit friends, families, and colleagues for donations. They in turn are expected to share the URL of the fundraising webpage and the solicitation message or their donations with their social and professional associates. Accordingly, most donors on a webpage likely belong to an NPO's or fundraiser's existing networks. Donors can also register with JapanGiving and can donate by credit card or through Internet banking.

\subsection{Characteristics of donation data}

We use data from 9,989 donations made via JapanGiving from February 2011 to December 2011. ${ }^{6}$ All sampled donors viewed the same webpage design during this period. Although JapanGiving sometimes changed the design, such changes did not occur within the time period under which those 9,989 donations were made. JapanGiving records the monetary amounts of donations, their dates and times, and the recipient organizations. We use these data to generate further information. First, we identify the order of donations within a campaign webpage from the time and date data. Subsequently, we use the amounts donated and their sequence to calculate totals already donated pending the next donation. This allows us to capture the information that each donor saw when they visited the webpage. We identified donors by randomly assigned IDs and gathered no personal information.

\footnotetext{
${ }^{4}$ The platform's name changed from JustGiving Japan to JapanGiving on 21 January 2015.

51 US dollar is equivalent to 79.7905 Japanese yen in 2011.

6 The total number of donations within this period was 67,595. Most of them pertained to the reconstruction process from the Great East Japan Earthquake and Tsunami in 2011. We selected the sample for our analysis from the 67,595 donations by following the procedure in Subsection 4.2, and obtained plausibly homogeneous sample.
} 


\subsection{List of previous donations}

The unique feature of JapanGiving is that it lists all previous donations (Figure 1). Its list includes a donor's name, comments, date and time of donation, and contribution. Information is displayed chronologically on one electronic page. A donor sees the amount of each donation among several preceding ones because the normal browser can display the preceding four or five donations.

[Figure 1 is here]

The donor sees the distribution of the immediately preceding five donations and their variation. They consider the variation as large when the previous five donors have given different amounts and small when each has given a similar or identical amount. If findings from social psychology apply to charitable giving, the influence of the preceding five donations is larger in the latter case than in the former. The affected donation could follow the modal donation among the previous five donations. 


\section{Empirical strategy}

\subsection{Model specifications and variables}

To examine a spread of conformity behaviors, we estimate the equations specified in the following two ways. In the first model, we investigate whether positive causality runs from the conformity behavior of a previous donor to that of a new donor. In other words, when a previous donor imitate the amount that another previous donor has made, a subsequent donor will likely match their amount. The hypothesis tested is that when the two most recent donations are identical, a new donor will likely match the immediately preceding donation. In the second model, we investigate the hypothesis that when more previous donors conform, new donor conformity is strengthened. In particular, the hypothesis tested is that when the number of the most recent continuous modal donations increases among the immediately preceding five donations, a new donor is more likely to match the modal amount.

\subsubsection{Model (1)}

The first model is as follows: ${ }^{7}$

$$
\begin{gathered}
\operatorname{Pr}\left(y_{i, t}=1\right)=\alpha+\gamma y_{i, t-1}+z^{\prime}{ }_{i, t} \delta+u_{i, t} \\
y_{i, t}=1, \text { if } d_{i, t}=d_{i, t-1} \\
y_{i, t}=0, \text { if } d_{i, t} \neq d_{i, t-1}
\end{gathered}
$$

Empirical Hypothesis 1: When the two most recent donations are identical, a new donor will likely match the immediately preceding donation.

where $d_{i, t}$ refers to the amount of the $t^{\text {th }}$ donation to a campaign webpage $i$.

The dependent variable $y_{i, t}$ is a dummy that takes 1 when $d_{i, t}$ exactly equals $d_{i, t-1}$, and 0 otherwise. We define that $t^{t h}$ donor conforms to $t-1^{t h}$ donor when $d_{i, t}$ and $d_{i, t-1}$ are identical. Some might argue that this definition is too strict, because it judges that $t^{t h}$ donor does not conform to $t-1^{t h}$ donor even when $d_{i, t}$ and $d_{i, t-1}$ are

\footnotetext{
7 To examine the existence of donor conformity, we estimated the following model: $d_{i, t}=\alpha+\gamma d_{i, t-1}+$ $z_{i, t}^{\prime} \delta+u_{i, t}$. The estimated results showed that $\gamma$ is small and insignificant. This implies that a new donor does not respond only to a change in a single immediately preceding donation. This result led us to look at combinations of multiple previous donations.
} 
almost, but not exactly, the same. This definition can underestimate the parameters in our model. We nevertheless define so because of the following three perspectives. First, if we find out the expected parameter directionality from the underestimated results, it strongly supports our hypothesis. It also clearly can provide academic and practical implications. Second, social psychology studies examine whether an individual choice exactly equals others', to our knowledge. Third, this definition is based on the JapanGiving payment system. The JapanGiving payment provides nine options for donated amounts. ${ }^{8}$ Over 90 percent of all donations coincide with amounts presented in the options. Donors could decide their contribution by choosing from the options, and they could make a binary decision of whether they select the option that other previous donors selected.

The independent variable $y_{i, t-1}$ is the first lag of the dependent variable $y_{i, t}$. This variable expresses whether the $t-1^{t h}$ donor conforms to the $t-2^{\text {th }}$ donor. Its parameter $\gamma$ equals the degree of an effect of the $t-1^{t h}$ donor's conformity behavior on that of the $t^{\text {th }}$ donor. If $\gamma>0$ holds true, it confirms our first empirical hypothesis and also suggests positive causality running from conformity behavior of a previous donor to that of a new donor.

\subsubsection{Model (2)}

Note that the independent variable $y_{i, t-1}$ potentially includes the cases where $d_{i, t-1}$, the amount of the $t-1^{t h}$ donation, equals not only $d_{i, t-2}$ but also $d_{i, t-3}, d_{i, t-4}$, or $d_{i, t-5}$. Then, the second model subdivides $y_{i, t-1}$ into several cases. By so doing, we test the second empirical hypothesis as follows:

$$
\begin{aligned}
\operatorname{Pr}\left(y_{i, t}=1\right)=\alpha+\gamma_{1} y_{i, t-1}+\gamma_{2} \mathrm{~T} 2_{i, t}+\gamma_{3} \mathrm{~T} 3_{i, t}+\gamma_{4} \mathrm{~T}_{i, t}+\gamma_{5} \mathrm{OT}_{i, t}+z^{\prime}{ }_{i, t} \delta \\
+u_{i, t}, \quad
\end{aligned} \begin{aligned}
(2) \\
y_{i, t}=1, \text { if } d_{i, t}=d_{i, t-1} \\
y_{i, t}=0, \text { if } d_{i, t} \neq d_{i, t-1}
\end{aligned}
$$

Empirical Hypothesis 2: When the number of the most recent continuous modal donations increases, a new donor is more likely to match the modal amount.

[Figure 2 is here]

\footnotetext{
8 They are (proportion of donations consistent within the nine options): $¥ 500$ (2.0 per cent), ¥1,000 (8.5 per cent), $¥ 2,000$ (13.3 per cent), ¥3,000 (12.2 per cent), ¥5,000 (25.8 per cent), ¥10,000 (25.4 per cent), $¥ 30,000$ (3.1 per cent), $¥ 50,000$ (0.9 per cent) and $¥ 100,000$ (0.9 per cent).
} 
Figure 2 draws what the main independent variables imply. The first lagged dependent variable $y_{i, t-1}$ is a dummy that takes 1 when $d_{i, t-1}$ at least equals $d_{i, t-2}$. Next, T1 $1_{i, t}$, $\mathrm{T} 2_{i, t}, \mathrm{~T} 3_{i, t}$, and $\mathrm{T} 4_{i, t}$ are dummies that take 1 when the only two most recent donation of $d_{i, t-1}$ and $d_{i, t-2}$ are identical, when the three most recent donation of $d_{i, t-1}, d_{i, t-2}$, and $d_{i, t-3}$ are identical, when the four most recent donation of $d_{i, t-1}, d_{i, t-2}, d_{i, t-3}$, and $d_{i, t-4}$ are identical, and when all of the immediately preceding five donations have an identical amount, respectively. Further, $\mathrm{OT}_{i, t}$ is a dummy that takes 1 when the first lagged dependent variable takes 1 but when all of $\mathrm{T} 1_{i, t}, \mathrm{~T} 2_{i, t}, \mathrm{~T} 3_{i, t}$, and $\mathrm{T} 4_{i, t}$ take zero. What is important here is that $y_{i, t-1}$ takes 1 in all the above treatments.

We interpret the parameters in the following ways. $\gamma_{1}$ exhibits the effect of treatment 1 on the probability that the dependent variable, $y_{i, t}$, takes $1 . \gamma_{1}+\gamma_{2}, \gamma_{1}+\gamma_{3}$, and $\gamma_{1}+\gamma_{4}$ are the effects of treatment 2 , treatment 3 , and treatment 4 , respectively.

$\mathrm{T} 1_{i, t}$ explains the largest variation among the five most recent donations, whereas $\mathrm{T} 4_{i, t}$ explains the smallest variation. We define the degree of conformity among the five most recent donors to be weakest in the former case, with the degree of conformity getting stronger in the order of $\mathrm{T} 2_{i, t}, \mathrm{~T} 3_{i, t}$, and $\mathrm{T} 4_{i, t}$.

We explain the degree of conformity among the five immediately preceding donors by constructing the variables of numbers of the most recent continuous modal donations. We set the variables in that way to consider the difference in the salience of modal donations between larger and smaller variations. For example, a donor might not recognize when two donations of the modal amount appear at an interval; however, they could more easily do so when the immediately preceding first and second donations are identical.

This methodology is simple and pragmatic for the purposes of hypothesis testing; however, we nevertheless recognize that it is difficult to compare the effects of treatments 1-4 and the effect of the other treatments. Because "others" are the cases in which multiple donations of the modal amount appear at an interval, their effects could resemble those of treatments 2-4. However, it is important to note that the hypothesis testing does not require a comparison between treatments 2-4 and the other treatments. In our model, if $0<\gamma_{2}<\gamma_{3}<\gamma_{4}$ holds true, it confirms our second empirical hypothesis and also supports our contention that when more previous donors donate similar amounts, the conformity of the new donor strengthens.

\subsubsection{Other components}

In both models, the control variables $z^{\prime}{ }_{i, t}$ include certain information that the $t^{\text {th }}$ donor 
sees on the webpage, such as the number of previous donations and the target completion rate. $z^{\prime}{ }_{i, t}$ also includes the duration from the inception of the webpage to the date of the $t^{t h}$ donation. Furthermore, we use monthly, weekday, and time zone dummies to accommodate common shocks among time intervals.

The error term is decomposed as $u_{i, t}=\eta_{i}+v_{i, t} . \eta_{i}$ is a constant page-specific effect that captures unobserved inter-donor preference correlations on that page; $v_{i, t}$ is a random error term. In view of the characteristics of the error term, the OLS estimates of $\gamma$ and $\gamma_{1-4}$ are likely to be upward-biased because of unobserved correlations. To exclude this bias, we use fixed effects linear probability models, estimating the above two equations.

However, the fixed effects estimates of $\gamma$ and $\gamma_{1-4}$ are likely to be downward-biased (Nickell, 1981) since the two models are dynamic panel models that include lags of the dependent variable. A correlation exists between treatment variables and the error term even after we eliminate a constant page-specific effect by first differencing.

We deal with this downward bias by the following two methodologies. The first methodologies are generalized moment methods (GMM) for dynamic panel estimations, which are called Difference GMM (Arellano and Bond, 1991) and System GMM (Bulundell and Bond, 1998). The second is a half-panel jackknife fixed effects estimation, which was developed by Dhane and Jochmans (2015).

In Difference GMM, we use as instruments the several period lags of the dependent variable that influence just the differenced independent variable after we eliminate the constant page-specific effect by first differencing. System GMM adds the level moment condition to the moment conditions of Difference GMM and estimate the equation.

We use another (second) methodology to deal with the downward bias. This is because some studies suggest that GMM estimates are not always stable because of the problems of weak instruments, too many instruments, and non-stationarity of the dependent variable (Roodman, 2009a; Bun et al., 2015). To overcome these problems, econometricians have developed another methodology by which they directly exclude the downward bias in the fixed effects estimates and obtain reliable estimates (Kiviet, 1995; Hahn and Kuersteiner, 2002; Bun and Carree, 2005; Dhane and Jochmans, 2015). We use the half-panel jackknife fixed effects estimation method on them, which was developed by Dhane and Jochmans (2015) and has been applied in recent empirical literature (Hospido, 2012, 2015). In this method, we first assume that the fixed effects estimator includes the downward bias $B$ and that $B$ decreases as the time $T$ dimension increases. Next, we estimate the fixed effects estimates of $\hat{\theta}_{n T}$ by using the full-panel dataset; $\hat{\theta}_{n T}$ 
includes the downward bias $B / T$. We also divide the full panel into the first half and the second half and estimate the fixed effects values of $\hat{\theta}_{n T, 1}$ and $\hat{\theta}_{n T, 2}$ by using the subsamples. $\hat{\theta}_{n T, 1}$ and $\hat{\theta}_{n T, 2}$ include the common downward bias $2 B / T$. Finally, we obtain the half-panel jackknife estimator without the downward bias by substituting $\hat{\theta}_{n T}$, $\hat{\theta}_{n T, 1}$, and $\hat{\theta}_{n T, 2}$ for the following:

$$
2 \widehat{\theta}_{n T}-\frac{\hat{\theta}_{n T, 1}+\hat{\theta}_{n T, 2}}{2}
$$

\subsection{Preliminary identification analysis}

Our identification strategy for the parameters of $y_{i, t-1}$ and $\mathrm{T} 2_{i, t}-\mathrm{T} 4_{i, t}$ assumes that donors' attributes and characteristics do not depend on $t$ after controlling a constant page-specific effect by fixed effects estimations or dynamic panel estimations. Ordinal regressions corroborate this assumption by directly adding variables of attributes and preferences to the equation: however, we gathered no personal information for its protection. Subsequently, we justify the assumption by confirming that the distribution of donated amounts on a webpage is stationary throughout the campaign. In that case, we can judge that homogeneous donors visit the campaign webpage and donate there. This subsection delineates examples to confirm the assumption.

First, we consider that distributions of donated amounts, the number of donors per webpage, and the length of the campaign are skewed because of a few successful fundraisers ${ }^{9}$ and generous donors (Smith, Windmeijer, and Wright, 2015). We exclude from analysis webpages that have single donations exceeding $¥ 500,000$ (US\$6,266.410), webpages with fewer than 25 , with more than 100 donations, or with donations more than 50 days after inception of the webpage. Furthermore, we exclude some exceptional donations, including continuous donations made by an identical donor and donations made by JapanGiving founders before a campaign webpage opens to public.

Second, we exclude the first three donations on each webpage because their donors are more likely to be the fundraiser's friends, family, and colleagues and tend to donate different amounts (Agrawal et al., 2014; Smith et al., 2015) ${ }^{10}$. Data indicates that the mean

\footnotetext{
${ }^{9}$ One of the most successful fundraisers is Dr. Shinya Yamanaka, a Japanese Nobel Prize-winning stem cell researcher. He raised more than $¥ 20,000,000$ (US\$250,656.406) from 1,913 donors; the largest single donation in his campaign was $¥ 1,000,000$ (US $\$ 12,532.820$ ).

10 Agrawal et al. (2014) use data from a Canadian crowdfunding platform, showing that early donors have closer relationships with fundraisers. Smith et al. (2015) reported that the average amount of the first three donations is systematically larger than the average of the remainder in JustGiving UK; therefore, they excluded the initial three donations in their analysis.
} 
of the first three donations ( $¥ 17,469.440$ ) significantly exceeds the mean of the remaining donations $(¥ 8,568.297)$ with statistical significance. Therefore, we exclude them. Furthermore, we exclude the fourth and fifth donations because our analysis focuses on the effects of the five immediately preceding donations.

Finally, we verify that amounts without the initial five donations are sufficiently stationary throughout the entire campaign. We divide donations on a campaign webpage into a first half and a second half depending on their timing. Then, we use the Kolmogorov-Smirnov test to compare the distribution of monetary amounts donated in both halves. The null hypothesis is that the two sample groups have identical distributions, and the test does not reject this in 291 out of 359 campaign webpages ( $p>0.100)$. Thus, the 9,989 data points across the 291 campaign webpages are plausibly homogeneous.

Before estimations, we introduce descriptive statistics of our samples. As seen in Table 1 , the arithmetic mean donation is $¥ 8,822.585$ (US\$110.572). The mean number of donations per campaign webpage is approximately 47 , and the mean target price is $¥ 997,724$ (US\$12,504.296). The number of campaigns with final target completion rates of 100 percent or more is 98 .

The arithmetic mean donation on JapanGiving might be higher than normal donations in Japan. One possible explanation is that most samples donated for the reconstruction process from the Great East Japan Earthquake and Tsunami and that such donations are likely to be higher. GivingJapan 2012 (Japan Fundraising Association, 2013) reports that relief money or donations averaged around $¥ 10,000$ across the nation. In other words, our data enables us to investigate the details of effects of previous modal donations in lower monetary ranges than the arithmetic mean donation.

[Table 1 is here] 


\section{Basic analysis}

This section first presents the estimation results of model (1), testing the first empirical hypothesis that when the two most recent donations are identical, a new donor will likely match the immediately preceding donation. Next, we present the estimation results of model (2), testing the second empirical hypothesis that when the number of the most recent continuous modal donations increases, a new donor is more likely to match the modal amount. We run the regressions, considering the control variables' effects, several fixed effects, and serial correlation effects.

\subsection{First hypothesis test results}

Table 2 presents the results of OLS estimations, fixed effects model estimations, and dynamic panel model estimations for comparison. In the Difference GMM and System GMM estimations, we use more than the two-period lags of the dependent variable and more than the three-period lags of the donation amount as instrumental variables. In addition, we collapse these instrumental variables to deal with the problem of excessive instrumental variables. It is because too many instrumental variables could over-fit endogenous variables and also weaken the Hansen test of over-identifying restrictions. 1112 The Arellano-Bond test for serial correlation does not reject the null hypothesis of no second-order serial correlation, implying that more than the two-period lags are valid as instruments. The Hansen test indicates that the instrument set is plausible.

The estimated results are basically consistent with the theoretical predictions for biases. The fixed-effects estimate is smaller than the OLS estimate. The OLS estimate is biased upward. All the dynamic panel estimates of $\gamma$ lie between the OLS estimate and the fixed effects estimate. The fixed effects estimate is biased downward.

[Table 2 is here]

Our finding confirms the first empirical hypothesis. Table 2 shows that all the dynamic panel estimates of $\gamma$ are positive and statistically significant at the 1 percent level. To

11 The econometric software STATA provides "collapse" option (Roodman, 2009b).

12 Several empirical studies in macroeconomics have reported plausible causal effects using GMM estimations, but these results suffered from problems associated with excessive instruments (Bazzi and Clemens, 2013). After collapsing the instruments to address these problems, most analyses showed no evidence that supported causality. 
elaborate on this, we find that when the two immediately preceding donations are identical, the likelihood that a new donor matches the immediately preceding donation increases by 13.0 percent-13.7 percent. This also supports the notion of positive causality running from conformity behavior of the most recent donor to that of a new donor. ${ }^{13}$

The magnitudes can be underestimated, as discussed in Subsection 4.1.1. It is because we define that $t-1^{t h}$ donor conforms to $t-2^{t h}$ donor when $d_{i, t-1}$ and $d_{i, t-2}$ are identical, and this definition allows the control group to include the case where $d_{i, t-1}$ and $d_{i, t-2}$ are almost, but not exactly, the same. The above results show that even if employing this strict definition, the magnitudes exceed 10.0. This implies that we cannot ignore the effect of conformity behavior of previous donors on that of a new donor.

\subsection{Second hypothesis test results}

Model (2) subdivides $y_{i, t-1}$ into five cases. We estimate this model, testing that when the number of the most recent continuous modal donations increases, a new donor is more likely to match the modal amount.

Before presenting the estimation results, we reintroduce the parameters associated with the key independent variables. First, $\gamma_{1}$ is the parameter of the first lagged dependent variable, which takes 1 when the at least two immediately preceding donations are identical. Second, $\gamma_{2}, \gamma_{3}$, or $\gamma_{4}$ is the parameter for each case of the three most recent continuous modal donations (treatment 2), the four most recent continuous modal donations (treatment 3 ), or the five or more most recent continuous modal donations (treatment 4). The baseline is the two most recent continuous modal donations (treatment 1). Third, $\gamma_{5}$ is the parameter of the other cases (other treatments), in which multiple donations of the modal amount appear at an interval. Finally, we interpret the parameters in the following ways. $\gamma_{1}$ exhibits the effect of treatment 1 on the probability that the dependent variable, $y_{i, t}$, takes 1. $\gamma_{1}+\gamma_{2}, \gamma_{1}+\gamma_{3}$, and $\gamma_{1}+\gamma_{4}$ are the effects of treatment 2 , treatment 3 , and treatment 4 , respectively.

\section{[Table 3 is here]}

Our findings confirm the second empirical hypothesis. According to Table 3, almost the dynamic panel estimates of $\gamma_{1} \cdot \gamma_{2} \cdot \gamma_{3} \cdot \gamma_{4}$ are positive and statistically significant

\footnotetext{
13 It is noteworthy that even the fixed effects estimate with a downward bias shows a positive and statistically significant effect. From the fixed effects estimation results, our data facilitates the derivation of the finding that conformity behavior of the previous donor is causative of new donor behavior.
} 
at least at the 5 percent level. ${ }^{14}$ Our additional tests show that $\gamma_{2}<\gamma_{3}<\gamma_{4}$. In other words, the effect gets larger in the order of treatment 1 , treatment 2 , treatment 3 , and treatment 4 . These results imply that, as the number of the most recent continuous modal donations increases among the five immediately preceding donations, the more likely a new donor is to match the immediately preceding donation. This confirms our second empirical hypothesis and also supports our contention that when more previous donors have contributed similarly in monetary terms, new donor conformity is strengthened.

[Table 4 is here]

Table 4 shows that the effects of treatment 2, treatment 3, and treatment 4 are 1.8 times, 3.1 times, and 5.3 times, respectively, larger than treatment $1 .{ }^{15}$ A new donor conformity strengthens not strictly linearly but continuously with the number of the most recent continuous modal donations.

The effect of treatment 1 is smaller than any of treatments 2,3 , and 4 because a new donor might recognize that the two most recent continuous modal donations are not the majority among the five immediately preceding donations. In some cases, the other three donors each match in terms of amount given, which is different from the immediately preceding donation requirement. When facing those cases, a subsequent donor might not think that many previous donors contribute the same amount as the immediately preceding donation. On the contrary, the three or more most recent donations are identical in treatments 3,4 , and 5 . A new donor might recognize that the immediately preceding donor belongs to the majority.

The Appendix shows that when multiple modal donations appear at intervals, a new donor will likely match the modal donation. This result implies that subsequent donors could recognize that many previous donors contributed the same amount, when multiple modal donations appear not only at no interval but also at some intervals. The result more directly supports the contention that a donor conforms to the majority's behavior.

\footnotetext{
${ }^{14}$ Similarly in model (1), the Arellano-Bond test and the Hansen test imply that our instrumental variables are valid and plausible.

${ }^{15}$ As an example, we use the Difference GMM estimations to conduct the additional tests and present the test results.
} 


\section{Further analyses}

\subsection{Heterogeneity between monetary amount ranges}

The effects of the most recent continuous modal donations can be observed particularly in lower ranges of contributions. A donor might easily match the most recent continuous modal donations with a lower amount (e.g., $¥ 3,000$ or US $\$ 37.590$ at the 2011 exchange rate) but not those with a higher amount (e.g., $¥ 30,000$ or US\$375.906).

We construct interaction terms between the dummies for ranges in amounts donated and variables of continuous modal donations. We use these variables, investigating whether the effects are strongly observed in lower ranges of donation amounts.

[Table 5 is here]

Table 5 presents the findings consistent with our predictions. First, the dynamic panel analysis of half-panel jackknife finds that the donation amounts ranges of $¥ 5,000$ $¥ 29,999$ themselves have positive and statistically significant effects. Also in the other dynamic panel analyses, the effects of these ranges are statistically and significantly larger than those of the ranges of $¥ 2,000-¥ 4,999$. These results imply that when the immediately preceding donor contributes in the ranges of $¥ 5,000-¥ 29,999$, a subsequent donor will likely contribute in these similar ranges even if they do not see the most recent continuous modal donations. In our samples, the average donation amount is $¥ 8,822.585$, and more than 50 percent of the samples donates in these high ranges of $¥ 5,000-¥ 29,999$, as introduced in Subsection 4. These sample characteristics could cause the above effects.

Second, in contrast, we cannot find the larger or stronger effects of the most recent continuous modal donations in these high ranges of $¥ 5,000-¥ 29,999$. Table 5 shows that the effects of the most recent three or more continuous modal donations are positive and statistically significant in the ranges of $¥ 1-¥ 1,999$ and $¥ 3,000-¥ 9,999$ in some dynamicpanel analyses: ${ }^{16}$ however, the effect is not statistically significant in the range of $¥ 10,000-¥ 29,999$ (at 5 percent level). In addition, the effects in the lower ranges is larger than that in the range of $¥ 5,000-¥ 9,999$. These results imply that when the most recent three or more continuous modal donations are identical in the lower ranges, a subsequent donor is likely to match the modal amount, but the likelihood decreases in the higher

${ }^{16}$ Our System GMM estimation demonstrates that the three or more continuous modal donations that are the most recent have a positive significant effect on the highest range of 50,000 yen or more. However, this case should be ignored because it is observed only once, thus rendering the results unreliable. 
ranges.

Our findings call fundraisers' attention to information on previous modal donations in lower amount ranges. It is because the information could stick subsequent donors to the lower ranges. Fundraisers need to enhance subsequent contributions, by newly providing information on another single donation or multiple modal donations of higher amounts. However, it should be noted that the modal donations of too high amounts would not have conformity effects on a new donor.

\subsection{Sample-selection issues}

Some might still argue that the most recent continuous modal donations hold positive effects because information regarding modal donations attracts different groups of donors. This concern relates to sample homogeneity. Even though we recognize that our dynamic panel approach accommodates this problem, we take another approach to readdress the concern. However, it is difficult to directly test the existence of a sample selection bias because we lack information regarding webpage traffic and donor characteristics. Instead, we use information regarding the arrival rate of donations (i.e., the duration from the $n-1^{\text {th }}$ donation to the $n^{\text {th }}$ donation). Since the arrival of a different group of donors would coincide with changes in arrival rates, we can investigate the existence of a sampleselection bias indirectly by investigating continuous changes in modal donations and the arrival rate of subsequent donations.

To address this concern, we use three dependent variables: ${ }^{17}$ (1) Whether a donor appears and donates within three hours after the immediately preceding donation, (2) whether a donor appears and donates between three hours and one day after the immediately preceding donation, (3) whether a donor appears and donates between one day and three days after the immediately preceding donation. If information regarding continuous modal donations attracts different cohorts of donors, the continuous modal donations should exert statistically significant effects on these dependent variables.

[Table 6 is here]

Results in Table 6 assuage the concern. They show that continuous modal donations

17 (1) 49.0 per cent of donors appear and donate within three hours after the immediately preceding donation, (2) 32.5 per cent of them appear and donate between three and twenty-four hours after the immediately preceding donation, and (3) 9.7 per cent of them appear and donate between one and three days after the immediately preceding donation. 
display no statistically significant effects; these findings do not support possibility of a sample-selection bias. E.g., a donor might seek out a campaign webpage that displays the immediately preceding continuous modal donations and donate there. If so, their information should have statistically significant positive impacts; however, this is not the case. Conversely, a donor might rather avoid a campaign webpage that displays continuous modal donations. If so, their information should have statistically significant negative impacts. Again, this is not the case. Finally, fundraisers might ask families, friends, and colleagues to make donations of a similar amount. If so, continuous modal donations should have statistically significantly positive impacts. However, once again, this is not the case. 


\section{Discussion, implications, limitations and future research}

We investigated how presenting amounts of multiple previous charitable contributions affects subsequent donations. Using data from a donation-based crowdfunding platform in Japan, we found that when the number of the most recent continuous modal donations increases among the immediately preceding five donations, a subsequent donor is more likely to match the modal amount. This implies that a donor conforms to the majority's behavior and that donor conformity is strengthened when the size of the majority expands.

Our findings are consistent with those of social psychological studies of conformity. Several experimental results in this field testify that people mirror the majority's behaviors and choices even if these behaviors and choices are made erroneously by the majority. Asch $(1951,1955)$ provides the most famous example. The author presents two cards to experimental subjects. The author posts just one line on one card and multiple lines on the other card. The author asks the subjects to select a line from the multiple lines on the latter card that equals the line on the former card. The main finding is that when knowing the fact that more of the group has selected the wrong choice, a subject is more likely to match this wrong choice.

We use these findings, first contributing to economic studies of charity. Several studies have shown that presenting a single donation influences a subsequent donor and increases the likelihood of their matching the presented donation (Alpizar et al., 2008; Shang and Croson, 2009). Our findings show that presenting multiple donations of a similar amount further strengthens the likelihood.

Second, this study contributes to raising the external validity of social psychological studies. Our findings imply that experimental results in social psychology are similarly observed in real charitable giving, which is an everyday occurrence. Even though laboratory studies on conformity started in the 1950s, a relatively small number of studies have established similar results in everyday situations (Claidière et al., 2012; Claidière et al., 2014).

Finally, this study contributes to improving online fundraising activities by charities not only academically but also practically. Our further analysis shows that when the most recent three or more continuous donations are identical in the low ranges, a subsequent donor is likely to match the modal amount, but the likelihood decreases in the higher ranges. These findings provides the possibility that knowing previous modal donations in lower amount ranges could stick subsequent donors to the lower amount ranges. Charities should struggle to enhance subsequent contributions, by newly providing information on 
donations of higher amounts.

However, even if the effects of the most recent three or more continuous donations weaken, the effects remain positive and statistically significant in some higher ranges. These findings indicate that charities can control the amounts contributed by subsequent donors, by presenting multiple donations of a similar amount.

If this strategy is useful for traditional/offline fundraising activities, we can contribute more to charities. Some previous studies have also indicated that charities can control contributions in the similar way by providing potential donors with already donated amounts from donors who share similar characteristics: however, this requires early knowledge of the characteristics of these potential and subsequent donors; obtaining this knowledge could be relatively expensive. Conversely, it is a simple and easy strategy to present multiple donations of a similar amount.

In sum, our findings suggest that charities alter the presented amounts accordingly to achieve their fundraising targets at a faster pace. This study can contribute to these objectives because we connect economic studies of charity and social psychological studies of conformity.

In what is common to most applied research, this study is not without its limitations. One limitation is that we could not explain why effects vary with the number of continuous modal donations. Field experimental studies often note this limitation. According to Zafar (2011), theoretical studies and laboratory experiments in economics and social psychology use different mechanisms to explain the relationship between individual conformity and others' behavior. The mechanisms are as follows: In the first mechanism of social learning, people learn about the best choice from information about others' choices and hence make the same choice (Banerjee, 1992; Bikhchandani et al., 1992). Although they might determine their best choice independently, doing so can be costly or time-consuming. Second, in social comparison, people increase their utility by simply mirroring others' choices (Cialdini, 1993; Messick, 1999). The third mechanism is image-related concerns. People stick to the same choice because they want to be considered generous. People who care about their own reputation tend to avoid their own choice's not coinciding with others' choices, because departures from the social trend can impair their social status (Bernheim, 1994; Andreoni and Petrie, 2004; Rege and Telle, 2004). The mechanism that explains the relationship depends on the context, and it is less clear as to which mechanism explains the relationship between donor conformity and the number of others contributing a similar amount. We expect future experimental research to discover a mechanism by which participants are allowed to browse contributions of 
multiple donors.

Despite the limitation, our conclusions are robust within our sample. This study and future research should extend the understanding of when donors are more likely to be influenced by other donors, which in turn will assist actual fundraising by charities. 


\section{Tables and Figures}

Figure 1. JapanGiving webpage

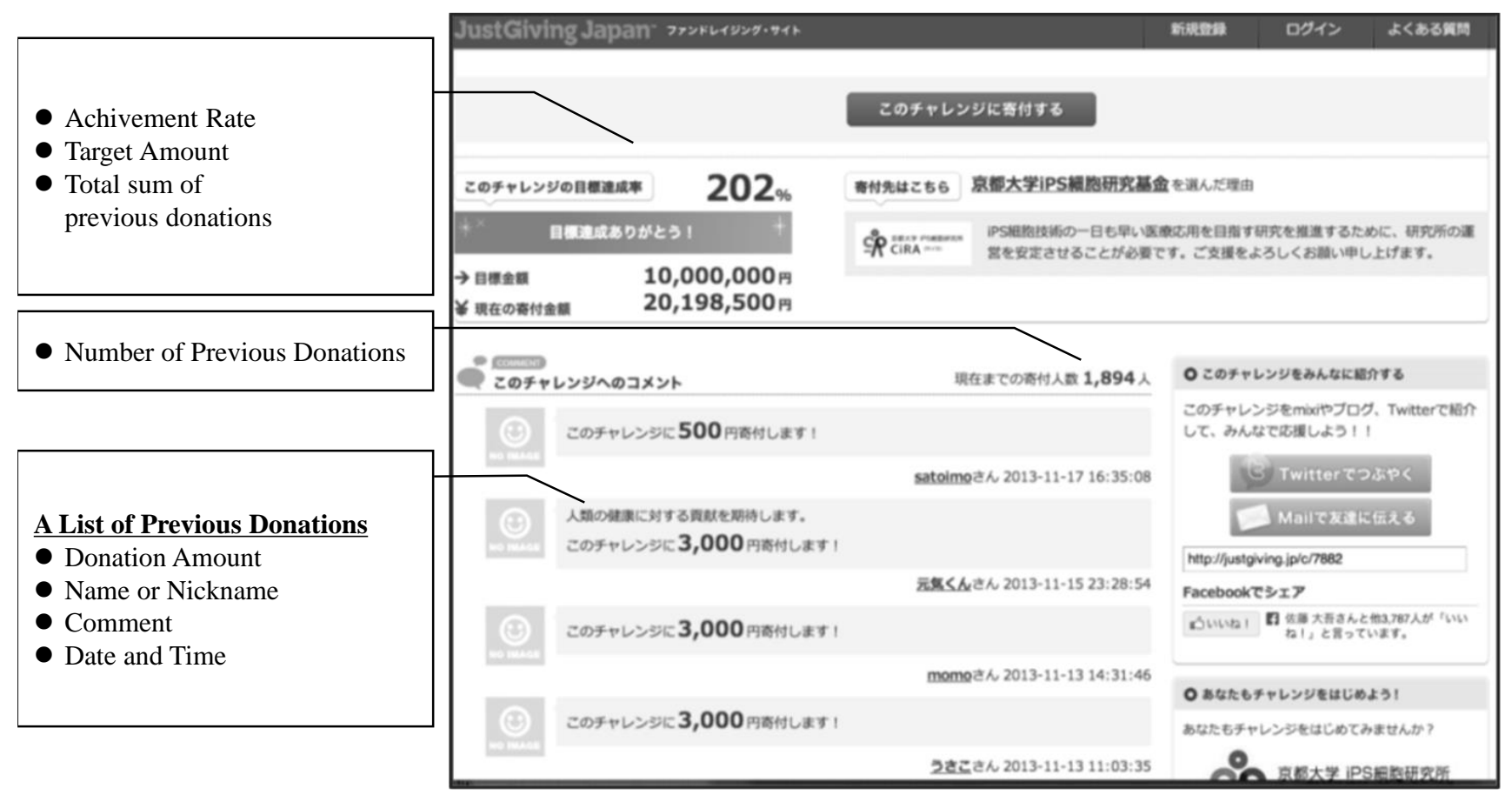

Notes

1. All sampled donors viewed the same webpage design.

2. The platform's name changed from JustGiving Japan to JapanGiving on 21st January 2015. 
Figure 2. Main independent dummy variables

\begin{tabular}{|c|c|c|c|c|c|c|c|c|c|c|c|}
\hline Main Independent Dummy Variables & $y_{i, t-1}$ & $\mathrm{~T} 1_{i, t}$ & $\mathrm{~T} 2_{i, t}$ & $\mathrm{~T} 3_{i, t}$ & $\mathrm{~T} 4_{i, t}$ & $\mathrm{OT}_{i, t}$ & $d_{i, t-1}$ & $d_{i, t-2}$ & $d_{i, t-3}$ & $d_{i, t-4}$ & $d_{i, t-5}$ \\
\hline $\begin{array}{l}\text { First Lagged Dependent Variable: } \\
\text { At Least Two Continuous Modal Donations }\end{array}$ & 1 & Base & $*$ & $*$ & $*$ & $*$ & 0 & 0 & $*$ & $*$ & $*$ \\
\hline $\begin{array}{l}\text { Treatment } 1 \text { (Basement): } \\
\text { Two Continuous Modal Donations }\end{array}$ & 1 & Base & 0 & 0 & 0 & 0 & O & 0 & $\mathrm{X}$ & $\mathrm{Y}$ & Z \\
\hline $\begin{array}{l}\text { Treatment 2: } \\
\text { Three Continuous Modal Donations }\end{array}$ & 1 & Base & 1 & 0 & 0 & 0 & 0 & 0 & 0 & $\mathrm{Y}$ & $\mathrm{Z}$ \\
\hline $\begin{array}{l}\text { Tretament 3: } \\
\text { Four Continuous Modal Donations }\end{array}$ & 1 & Base & 0 & 1 & 0 & 0 & 0 & 0 & 0 & 0 & Z \\
\hline $\begin{array}{l}\text { Treatment 4: } \\
\text { Five Continuous Modal Donations }\end{array}$ & 1 & Base & 0 & 0 & 1 & 0 & 0 & 0 & 0 & 0 & 0 \\
\hline Other Treatments: & 1 & Base & 0 & 0 & 0 & 1 & 0 & 0 & \multicolumn{3}{|c|}{$\begin{array}{l}\text { The other cases except } \\
\text { Treatments 1-4. }\end{array}$} \\
\hline
\end{tabular}

Notes: The circular marks explain donations of an identical amount. X, Y, and Z explain donations that are different from the amount. The asterisk marks imply that the donation amount is not conditional. 
Table1. Descriptive statistics

\begin{tabular}{lrrrr}
\hline & \multicolumn{1}{c}{ Mean } & \multicolumn{1}{c}{ Std. Dev. } & Min & Max \\
\hline Donation Unit, N=9,989 & & & & \\
Donation Amount (Japanese Yen) & $8,822.585$ & 19190.530 & 100 & 500,000 \\
& & & & \\
Campaign Webpage Unit, N=291 & & & 25 & 100 \\
Number of Donations & 46.856 & 19.091 & 77,777 & $10,000,000$ \\
Target Price (Japanese Yen) & $997,723.800$ & $1,621,552.000$ & 0.017 & 7.297 \\
Target Completion Rate & 0.822 & 0.733 & 0 & 1 \\
Over 100\% (Dummy Variable) & 0.337 & 0.473 & & 0 \\
\hline
\end{tabular}


Table 2. Basic analysis: Hypothesis 1 test results

\begin{tabular}{|c|c|c|c|c|c|}
\hline & (1) & (2) & (3) & (4) & (5) \\
\hline Linear Probability Model & OLS & Fixed Effects & Difference GMM & System GMM & Half Panel Jackknife \\
\hline $\begin{array}{l}\text { Model 1: } \\
\text { Lag1.dependent variable }\end{array}$ & $\begin{array}{c}0.163 * * * \\
(0.016)\end{array}$ & $\begin{array}{l}0.104 * * * \\
(0.014)\end{array}$ & $\begin{array}{c}0.136 * * * \\
(0.015)\end{array}$ & $\begin{array}{c}0.137 * * * \\
(0.015)\end{array}$ & $\begin{array}{l}0.130 * * * \\
(0.015)\end{array}$ \\
\hline N-1 th Donation Amount (Log-transformed) & $\begin{array}{l}-0.006 \\
(0.006)\end{array}$ & $\begin{array}{c}-0.011 * * \\
(0.004)\end{array}$ & $\begin{array}{c}-0.057 * * * \\
(0.007)\end{array}$ & $\begin{array}{c}-0.054 * * * \\
(0.006)\end{array}$ & $\begin{array}{c}-0.011 * * \\
(0.004)\end{array}$ \\
\hline Number of Previous Donations & $\begin{array}{c}-0.000 \\
(0.000)\end{array}$ & $\begin{array}{l}-0.001 * \\
(0.000)\end{array}$ & $\begin{array}{l}-0.001 \\
(0.003)\end{array}$ & $\begin{array}{l}-0.002 \\
(0.002)\end{array}$ & $\begin{array}{l}-0.000 \\
(0.001)\end{array}$ \\
\hline Target Completion Rate & $\begin{array}{c}-0.002 \\
(0.013)\end{array}$ & $\begin{array}{c}-0.005 \\
(0.013)\end{array}$ & $\begin{array}{c}-0.129 \\
(0.115)\end{array}$ & $\begin{array}{l}-0.015 \\
(0.026)\end{array}$ & $\begin{array}{l}-0.029 \\
(0.035)\end{array}$ \\
\hline From Inception of the Webpage & $\begin{array}{l}-0.001 \\
(0.001)\end{array}$ & $\begin{array}{c}0.001 \\
(0.001)\end{array}$ & $\begin{array}{c}0.004 \\
(0.004)\end{array}$ & $\begin{array}{l}-0.001 \\
(0.002)\end{array}$ & $\begin{array}{c}0.002 \\
(0.002)\end{array}$ \\
\hline Arellano-Bond test for $\mathrm{AR}(1)$, p-value & - & - & 0.000 & 0.000 & - \\
\hline Arellano-Bond test for $\mathrm{AR}(2)$, p-value & - & - & 0.922 & 0.914 & - \\
\hline Hansen test, p-value & - & - & 0.374 & 0.452 & - \\
\hline (over-ID restrictions) & - & - & $(13)$ & $(17)$ & - \\
\hline FE Campaign Webpage & NO & YES & YES & YES & YES \\
\hline FE Monthly & YES & YES & YES & YES & YES \\
\hline FE Weekday & YES & YES & YES & YES & YES \\
\hline FE Timezone & YES & YES & YES & YES & YES \\
\hline
\end{tabular}

Notes:

1. The number of donations is 9,989 , and the number of campaign webpages is 291 .

2. Cluster robust standard errors in parentheses $* * * \mathrm{p}<0.01$, ** $\mathrm{p}<0.05, * \mathrm{p}<0.1$.

3 . The dependent variable is a binary variable, which takes 1 when $\mathrm{n}$ th donation amount is equal to $\mathrm{n}-1$ th donation amount. 
Table 3. Basic analysis: Hypothesis 2 test results

\begin{tabular}{|c|c|c|c|c|c|c|c|c|c|c|}
\hline Linear Probability Model & & & & & & $\begin{array}{l}\text { (1) } \\
\text { OLS }\end{array}$ & $\begin{array}{c}\text { (2) } \\
\text { Fixed Effects }\end{array}$ & $\begin{array}{c}\text { (3) } \\
\text { Difference GMM }\end{array}$ & $\begin{array}{c}\text { (4) } \\
\text { System GMM }\end{array}$ & $\begin{array}{c}\text { (5) } \\
\text { Half Panel Jackknife }\end{array}$ \\
\hline Model 2: The Five Most Recent Donations & n-1 & n-2 & n-3 & $n-4$ & n-5 & & & & & \\
\hline Lag1.Dependent Variable & $\bullet$ & $\bullet$ & $*$ & $*$ & $*$ & $\begin{array}{c}0.044 * * \\
(0.018)\end{array}$ & $\begin{array}{c}0.019 \\
(0.018)\end{array}$ & $\begin{array}{c}0.070 * * * \\
(0.021)\end{array}$ & $\begin{array}{c}0.065 * * * \\
(0.021)\end{array}$ & $\begin{array}{c}0.039^{* * *} \\
(0.019)\end{array}$ \\
\hline Treatment 1 & • & $\bullet$ & $\mathrm{X}$ & $\mathrm{Y}$ & $\mathrm{Z}$ & Basement & Basement & Basement & Basement & Basement \\
\hline Treatment 2 & $\bullet$ & $\bullet$ & $\bullet$ & $\mathrm{Y}$ & $\mathrm{Z}$ & $\begin{array}{c}0.108^{* * * * *} \\
(0.033)\end{array}$ & $\begin{array}{c}0.073 * * \\
(0.033)\end{array}$ & $\begin{array}{c}0.058 \\
(0.036)\end{array}$ & $\begin{array}{l}0.075^{* *} \\
(0.036)\end{array}$ & $\begin{array}{l}0.080^{* * *} \\
(0.034)\end{array}$ \\
\hline Treatment 3 & $\bullet$ & ○ & ○ & • & $\mathrm{Z}$ & $\begin{array}{c}0.180^{* * * *} \\
(0.039)\end{array}$ & $\begin{array}{c}0.115 * * * * \\
(0.037)\end{array}$ & $\begin{array}{c}0.147 * * * \\
(0.047)\end{array}$ & $\begin{array}{c}0.162 * * * * \\
(0.046)\end{array}$ & $\begin{array}{c}0.131^{* * * *} \\
(0.038)\end{array}$ \\
\hline Treatment 4 & 0 & $\bullet$ & 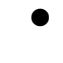 & 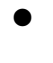 & $\bullet$ & $\begin{array}{c}0.351^{* * * *} \\
(0.039)\end{array}$ & $\begin{array}{c}0.245^{* * * *} \\
(0.036)\end{array}$ & $\begin{array}{c}0.300^{* * * *} \\
(0.046)\end{array}$ & $\begin{array}{c}0.317 * * * \\
(0.045)\end{array}$ & $\begin{array}{c}0.279 * * * \\
(0.046)\end{array}$ \\
\hline Other Treatments & $\bullet$ & ○ & $\begin{array}{l}\text { The ot } \\
\text { Treatm }\end{array}$ & $\begin{array}{l}\text { cases } \\
\text { ts } 1-4\end{array}$ & cept & $\begin{array}{c}0.137^{* * * *} \\
(0.024)\end{array}$ & $\begin{array}{c}0.113 * * * \\
(0.023)\end{array}$ & $\begin{array}{c}0.090^{* * * *} \\
(0.028)\end{array}$ & $\begin{array}{c}0.103 * * * \\
(0.026)\end{array}$ & $\begin{array}{c}0.114 * * * * \\
(0.023)\end{array}$ \\
\hline N-1 th Donation Amount (Log-transformed) & & & & & & $\begin{array}{l}-0.007 \\
(0.005)\end{array}$ & $\begin{array}{c}-0.011 * * \\
(0.004)\end{array}$ & $\begin{array}{c}-0.055^{* * * *} \\
(0.007)\end{array}$ & $\begin{array}{c}-0.052^{* * * * *} \\
(0.006)\end{array}$ & $\begin{array}{c}-0.011^{* *} \\
(0.004)\end{array}$ \\
\hline Number of Previous Donations & & & & & & $\begin{array}{l}-0.000 \\
(0.000)\end{array}$ & $\begin{array}{l}-0.001 * * \\
(0.000)\end{array}$ & $\begin{array}{l}-0.001 \\
(0.003)\end{array}$ & $\begin{array}{l}-0.001 \\
(0.002)\end{array}$ & $\begin{array}{l}-0.001 \\
(0.001)\end{array}$ \\
\hline Target Completion Rate & & & & & & $\begin{array}{l}-0.000 \\
(0.010)\end{array}$ & $\begin{array}{l}-0.006 \\
(0.012)\end{array}$ & $\begin{array}{l}-0.126 \\
(0.140)\end{array}$ & $\begin{array}{l}-0.013 \\
(0.025)\end{array}$ & $\begin{array}{l}-0.030 \\
(0.033)\end{array}$ \\
\hline From Inception of the Webpage & & & & & & $\begin{array}{l}-0.001 \\
(0.001)\end{array}$ & $\begin{array}{c}0.001 \\
(0.001)\end{array}$ & $\begin{array}{c}0.004 \\
(0.004)\end{array}$ & $\begin{array}{l}-0.001 \\
(0.001)\end{array}$ & $\begin{array}{c}0.002 \\
(0.002)\end{array}$ \\
\hline Arellano-Bond test for AR(1), p-value & & & & & & - & - & 0.000 & 0.000 & - \\
\hline Arellano-Bond test for AR(2), p-value & & & & & & - & - & 0.249 & 0.193 & - \\
\hline Hansen test, p-value & & & & & & - & - & 0.345 & 0.362 & - \\
\hline (over-ID restrictions) & & & & & & - & - & $(25)$ & (33) & - \\
\hline FE Campaign Webpage & & & & & & NO & YES & YES & YES & YES \\
\hline FE Monthly & & & & & & YES & YES & YES & YES & YES \\
\hline FE Weekday & & & & & & YES & YES & YES & YES & YES \\
\hline FE Timezone & & & & & & YES & YES & YES & YES & YES \\
\hline
\end{tabular}

Notes:

1. The number of donations is 9,989 , and the number of campaign webpages is 291 .

2. Cluster robust standard errors in parentheses $* * * x<0.01, * * \mathrm{p}<0.05$, * $\mathrm{p}<0.1$.

3. The dependent variable is a binary variable, which takes 1 when $\mathrm{n}$ th donation amount is equal to $\mathrm{n}-1$ th donation amount.

4. The circular marks explain donations of an identical amount. X, Y, and Z explain donations that are different from the amount. The asterisk marks imply that the donation amount is not conditional. 
Table 4. Effects on the probability that the dependent variable takes 1

\begin{tabular}{|l|l|}
\hline $\begin{array}{l}\text { Effect of Treatment 1: } \\
\text { Two Most Recent Continuous Modal Donations }\end{array}$ & $\gamma_{1}=0.070$ \\
\hline $\begin{array}{l}\text { Effect of Treatment 2: } \\
\text { Three Most Recent Continuous Modal Donations }\end{array}$ & $\gamma_{1}+\gamma_{2}=1.8 \times \gamma_{1}=0.127$ \\
\hline $\begin{array}{l}\text { Effect of Tretament 3: } \\
\text { Four Most Recent Continuous Modal Donations }\end{array}$ & $\gamma_{1}+\gamma_{3}=3.1 \times \gamma_{1}=0.217$ \\
\hline $\begin{array}{l}\text { Effect of Treatment 4: } \\
\text { Five Most Recent Continuous Modal Donations }\end{array}$ & $\gamma_{1}+\gamma_{4}=5.3 \times \gamma_{1}=0.370$ \\
\hline
\end{tabular}


Table 4. Further analysis: Heterogeneity between ranges of amounts

\begin{tabular}{|c|c|c|c|c|c|c|}
\hline & & (1) & (2) & (3) & (4) & (5) \\
\hline Linear Probability Model & & OLS & Fixed Effects & Difference GMM & System GMM & Half Panel Jackknife \\
\hline \multirow[t]{7}{*}{ N-th Donation Amount Ranges } & $\begin{array}{r}1-999 \text { yen } \\
1,000-1,999 \text { yen }\end{array}$ & Basement & Basement & Basement & Basement & Basement \\
\hline & $2,000-2,999$ yen & $\begin{array}{l}0.033^{*} \\
(0.019)\end{array}$ & $\begin{array}{l}0.020 \\
(0.019)\end{array}$ & $\begin{array}{l}-0.059 \\
(0.131)\end{array}$ & $\begin{array}{l}-0.026 \\
(0.106)\end{array}$ & $\begin{array}{c}0.023 \\
(0.019)\end{array}$ \\
\hline & $3,000-4,999$ yen & $\begin{array}{c}0.019 \\
(0.020)\end{array}$ & $\begin{array}{c}0.014 \\
(0.019)\end{array}$ & $\begin{array}{l}-0.145 \\
(0.161)\end{array}$ & $\begin{array}{l}-0.112 \\
(0.149)\end{array}$ & $\begin{array}{c}0.014 \\
(0.020)\end{array}$ \\
\hline & $5,000-9,999$ yen & $\begin{array}{c}0.119 * * * \\
(0.019)\end{array}$ & $\begin{array}{c}0.108^{* * * *} \\
(0.020)\end{array}$ & $\begin{array}{c}0.166 \\
(0.137)\end{array}$ & $\begin{array}{l}0.187 \\
(0.114)\end{array}$ & $\begin{array}{c}0.106^{* * * * *} \\
(0.020)\end{array}$ \\
\hline & 10,000 - 29,999 yen & $\begin{array}{c}0.107 * * * \\
(0.020)\end{array}$ & $\begin{array}{c}0.095 * * * \\
(0.020)\end{array}$ & $\begin{array}{c}0.185 \\
(0.128)\end{array}$ & $\begin{array}{l}0.202^{*} \\
(0.106)\end{array}$ & $\begin{array}{c}0.096 * * * \\
(0.020)\end{array}$ \\
\hline & 30,000 - 49,999 yen & $\begin{array}{c}-0.115^{* * * * *} \\
(0.017)\end{array}$ & $\begin{array}{c}-0.126^{* * * *} \\
(0.019)\end{array}$ & $\begin{array}{l}-0.487^{*} \\
(0.283)\end{array}$ & $\begin{array}{l}-0.395^{*} \\
(0.240)\end{array}$ & $\begin{array}{c}-0.123 * * * * \\
(0.019)\end{array}$ \\
\hline & 50,000 yen and more & $\begin{array}{c}-0.132 * * * \\
(0.016)\end{array}$ & $\begin{array}{c}-0.142^{* * * *} \\
(0.021)\end{array}$ & $\begin{array}{l}-0.265 \\
(0.177)\end{array}$ & $\begin{array}{l}-0.253^{*} \\
(0.151)\end{array}$ & $\begin{array}{c}-0.138^{* * * *} \\
(0.021)\end{array}$ \\
\hline \multirow[t]{9}{*}{ Lag1. dependent variable $\times \mathrm{N}$-th Donation Amount Ranges } & 1 - 999 yen & $\begin{array}{c}-0.052 \\
(0.067)\end{array}$ & $\begin{array}{l}-0.056 \\
(0.072)\end{array}$ & $\begin{array}{c}0.068 \\
(0.121)\end{array}$ & $\begin{array}{c}0.025 \\
(0.123)\end{array}$ & $\begin{array}{l}-0.037 \\
(0.078)\end{array}$ \\
\hline & $1,000-1,999$ yen & $\begin{array}{c}-0.022 \\
(0.039)\end{array}$ & $\begin{array}{l}-0.060 \\
(0.038)\end{array}$ & $\begin{array}{c}0.079 \\
(0.122)\end{array}$ & $\begin{array}{c}0.080 \\
(0.099)\end{array}$ & $\begin{array}{l}-0.050 \\
(0.039)\end{array}$ \\
\hline & $2,000-2,999$ yen & $\begin{array}{l}0.076^{*} \\
(0.043)\end{array}$ & $\begin{array}{l}0.035 \\
(0.044)\end{array}$ & $\begin{array}{l}0.179^{*} \\
(0.093)\end{array}$ & $\begin{array}{l}0.160^{*} \\
(0.084)\end{array}$ & $\begin{array}{c}0.068 \\
(0.047)\end{array}$ \\
\hline & $3,000-4,999$ yen & $\begin{array}{c}0.001 \\
(0.042)\end{array}$ & $\begin{array}{l}-0.027 \\
(0.043)\end{array}$ & $\begin{array}{l}0.168^{*} \\
(0.101)\end{array}$ & $\begin{array}{l}0.114 \\
(0.100)\end{array}$ & $\begin{array}{l}-0.004 \\
(0.044)\end{array}$ \\
\hline & $5,000-9,999$ yen & $\begin{array}{c}0.012 \\
(0.033)\end{array}$ & $\begin{array}{l}-0.005 \\
(0.033)\end{array}$ & $\begin{array}{l}-0.040 \\
(0.053)\end{array}$ & $\begin{array}{l}-0.025 \\
(0.051)\end{array}$ & $\begin{array}{l}0.015 \\
(0.034)\end{array}$ \\
\hline & 10,000 - 29,999 yen & $\begin{array}{l}0.069^{*} \\
(0.035)\end{array}$ & $\begin{array}{c}0.051 \\
(0.036)\end{array}$ & $\begin{array}{c}-0.004 \\
(0.058)\end{array}$ & $\begin{array}{l}0.005 \\
(0.054)\end{array}$ & $\begin{array}{l}0.069^{*} \\
(0.036)\end{array}$ \\
\hline & 30,000 - 49,999 yen & 0.154 & 0.133 & 0.467 & 0.400 & 0.162 \\
\hline & & $(0.115)$ & $(0.113)$ & $(0.321)$ & $(0.251)$ & $(0.145)$ \\
\hline & 50,000 yen and more & $\begin{array}{l}-0.023^{*} \\
(0.012)\end{array}$ & $\begin{array}{l}-0.046^{*} \\
(0.028)\end{array}$ & $\begin{array}{c}0.094 \\
(0.303)\end{array}$ & $\begin{array}{c}0.083 \\
(0.215)\end{array}$ & $\begin{array}{l}-0.001 \\
(0.049)\end{array}$ \\
\hline Treatment 1 & & Basement & Basement & Basement & Basement & Basement \\
\hline \multirow[t]{12}{*}{ Treatment 2,3 , or $4 \times \mathrm{N}$-th Donation Amount Ranges } & $1-999$ yen & $\begin{array}{c}0.110 \\
(0.096)\end{array}$ & $\begin{array}{c}0.104 \\
(0.073)\end{array}$ & $\begin{array}{c}0.289 \\
(0.194)\end{array}$ & $\begin{array}{c}0.373 * * \\
(0.163)\end{array}$ & $\begin{array}{c}0.097 \\
(0.080)\end{array}$ \\
\hline & $1,000-1,999$ yen & $\begin{array}{c}0.554 * * * \\
(0.099)\end{array}$ & $\begin{array}{c}0.413 * * * \\
(0.100)\end{array}$ & $\begin{array}{c}0.194 \\
(0.132)\end{array}$ & $\begin{array}{l}0.223^{*} \\
(0.120)\end{array}$ & $\begin{array}{c}0.475 * * * \\
(0.136)\end{array}$ \\
\hline & $2,000-2,999$ yen & $\begin{array}{c}0.029 \\
(0.071)\end{array}$ & $\begin{array}{l}-0.033 \\
(0.069)\end{array}$ & $\begin{array}{l}0.030 \\
(0.103)\end{array}$ & $\begin{array}{c}0.038 \\
(0.097)\end{array}$ & $\begin{array}{l}-0.036 \\
(0.073)\end{array}$ \\
\hline & $3,000-4,999$ yen & $\begin{array}{c}0.229 * * * \\
(0.075)\end{array}$ & $0.166^{* * *}$ & $0.221 * *$ & $0.298 * *$ & $\begin{array}{c}0.192 * * * * \\
(0.071)\end{array}$ \\
\hline & $5,000-9,999$ yen & $0.197 * * *$ & $0.140^{* * * * *}$ & $0.119 * *$ & $0.097 *$ & $\begin{array}{l}(0.071) \\
0.157 * * *\end{array}$ \\
\hline & & $(0.047)$ & $(0.046)$ & $(0.059)$ & $(0.059)$ & $(0.048)$ \\
\hline & $10,000-29,999$ yen & $0.132 * * *$ & 0.066 & 0.072 & 0.070 & $0.085^{*}$ \\
\hline & & $(0.047)$ & $(0.045)$ & $(0.060)$ & $(0.061)$ & $(0.047)$ \\
\hline & $30,000-49,999$ yen & 0.127 & 0.088 & 0.126 & 0.089 & 0.208 \\
\hline & & $(0.186)$ & $(0.197)$ & $(0.244)$ & $(0.260)$ & $(0.285)$ \\
\hline & 50,000 yen and more & 0.016 & 0.000 & 0.888 & $1.036^{* * * *}$ & -0.050 \\
\hline & & $(0.022)$ & $(0.035)$ & $(0.650)$ & $(0.371)$ & $(0.059)$ \\
\hline Arellano-Bond test for AR(1), p-value & & - & - & 0.000 & 0.000 & - \\
\hline Arellano-Bond test for AR(2), p-value & & - & - & 0.865 & 0.967 & - \\
\hline Hansen test, p-value & & - & - & 0.246 & 0.290 & - \\
\hline (over-ID restrictions) & & - & - & $(101)$ & $(134)$ & - \\
\hline Other Treatments $\times \mathrm{N}$-th Donation Amount Ranges & & YES & YES & YES & YES & YES \\
\hline Number of Previous Donations & & YES & YES & YES & YES & YES \\
\hline Target Completion Rate & & YES & YES & YES & YES & YES \\
\hline From Inception of the Webpage & & YES & YES & YES & YES & YES \\
\hline FE Campaign Webpage & & NO & YES & YES & YES & YES \\
\hline FE Monthly & & YES & YES & YES & YES & YES \\
\hline FE Weekday & & YES & YES & YES & YES & YES \\
\hline FE Timezone & & YES & YES & YES & YES & YES \\
\hline
\end{tabular}

Notes:

1. The number of donations is 9,989 , and the number of campaign webpages is 291 .

2. Cluster robust standard errors in parentheses *** $\mathrm{p}<0.01$, ** $\mathrm{p}<0.05, * \mathrm{p}<0.1$.

3 . The dependent variable is a binary variable, which takes 1 when $n$th donation amount is equal to $n-1$ th donation amount.

4. The regression includes control variables and 4 types of fixed effects. 
Table 5. Further analysis: Sample-selection issues

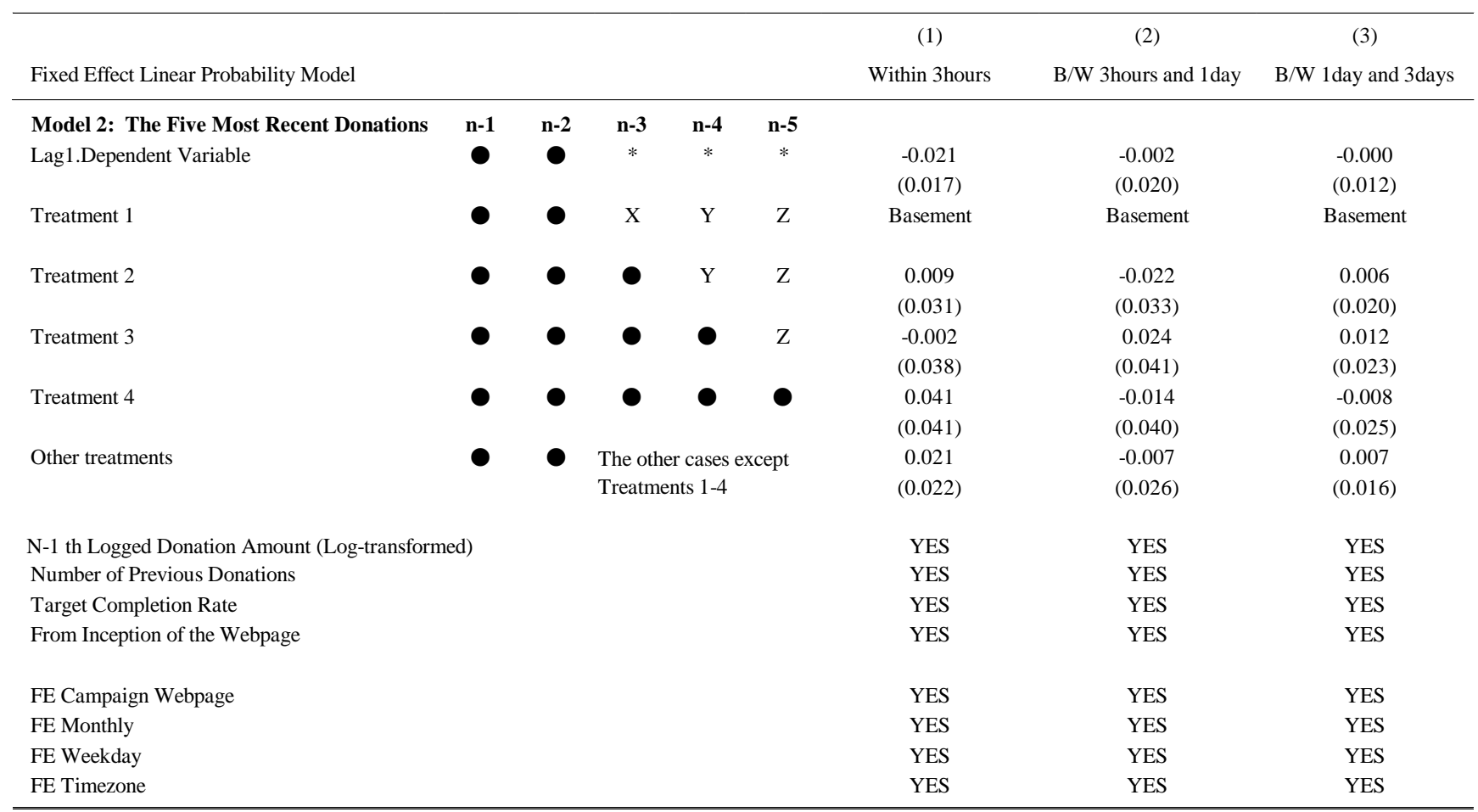

Notes:

1. The number of donations is 9,878 , and the number of campaign webpages is 290 .

2. Cluster robust standard errors in parentheses $* * * \mathrm{p}<0.01, * * \mathrm{p}<0.05, * \mathrm{p}<0.1$.

3. The dependent variable a binary variable, which takes 1

(1) when a donor appears and makes a donation within 3 hours after the immediately preceding first donation.

(2) when a donor appears and makes a donation between 3 hours and 1 day after the immediately preceding first donation.

(3) when a donor appears and makes a donation between 1 day and 3 days after the immediately preceding first donation.

4. All regressions include control variables and 4 types of fixed effects.

5. The circular marks explain donations of an identical amount. X, Y, and Z explain donations that are different from the amount. The asterisk marks imply that the donation amount is not conditional. 


\section{Appendix. Renewed model (2.2)}

Model (2) includes variables to explain the number of the most recent continuous modal donations because its number has a low cognitive cost for most donors. This methodology is simple and allows easy testing of our second hypothesis; however, it is difficult to compare the effects of treatments 1-4 and the effect of "other treatments." Because other treatments are the cases in which multiple donations of the modal amount appear at an interval, the parameter $\gamma_{5}$ could have a similar effect with treatments 1-4.

We reconstruct model (2), excluding "other treatments" from the model. In the renewed model (2.2), new treatments 1 and 4 are identical to treatments 1 and 4 . New treatment 2 or new treatment 3 is the case where $d_{i, t-1}$, the $n-1^{\text {th }}$ donation amount, equals $d_{i, t-2}$ and any one or two among $d_{i, t-3}, d_{i, t-4}$, and $d_{i, t-5}$. That is, these two treatments include "other treatments," where multiple donations of the modal amount appear among the five most recent donations at intervals even though the immediately preceding two donations are identical and fixed. Model (2.2) assumes that any donor recognizes $d_{i, t-2}$, $d_{i, t-3}, d_{i, t-4}$, and $d_{i, t-5}$ equally precisely.

$$
\begin{array}{r}
\operatorname{Pr}\left(y_{i, t}=1\right)=\alpha+\gamma_{\mathbf{1}} \boldsymbol{y}_{i, t-\mathbf{1}}+\boldsymbol{\gamma}_{\mathbf{2}} \mathbf{N T} \mathbf{2}_{\boldsymbol{i}, \boldsymbol{t}}+\boldsymbol{\gamma}_{\mathbf{3}} \mathbf{N T} \mathbf{3}_{\boldsymbol{i}, \boldsymbol{t}}+\boldsymbol{\gamma}_{\mathbf{4}} \mathbf{N T} \mathbf{4}_{\boldsymbol{i , t}}+z^{\prime}{ }_{i, t} \delta \\
+u_{i, t}, \quad(2.2) \\
y_{i, t}=1, \text { if } d_{i, t}=d_{i, t-1} \\
y_{i, t}=0, \text { if } d_{i, t} \neq d_{i, t-1}
\end{array}
$$

[Figure Appendix 1 is here]

We estimate the above model with these new variables, directly testing that when more previous donors contribute a similar amount, it is more likely that a new donor contributes the modal amount. The expected results are that the effect on the probability that the dependent variable, $y_{i, t}$, takes 1 is smallest in new treatment 1 , and it increases in the order of new treatment 2 , new treatment 3 , and new treatment 4.

[Table Appendix 1 is here]

Table Appendix 1 shows that the findings are consistent with our expectations. The dynamic panel estimates of $\gamma_{1} \cdot \gamma_{2} \cdot \gamma_{3} \cdot \gamma_{4}$ are positive and statistically significant at least at the 5 percent level. In addition, $\gamma_{2}<\gamma_{3}<\gamma_{4}$. 
These results show that a new donor is more likely to match the $n-1^{\text {th }}$ donation amount in the order of new treatment 1 , new treatment 2 , new treatment 3 , and new treatment 4 . These results support the contention that when more of the preceding five donors contribute an identical amount, a new donor is likely to contribute the modal amount. 
Figure Appendix 1. Main independent dummy variables in renewed model (2.2)

\begin{tabular}{|c|c|c|c|c|c|c|c|c|c|c|}
\hline Main Independent Dummy Variables & $y_{i, t-1}$ & $\mathrm{NT} 1_{i, t}$ & $\mathrm{NT} 2_{i, t}$ & $\mathrm{NT}_{i, t}$ & $\mathrm{NT} 4_{i, t}$ & $d_{i, t-1}$ & $d_{i, t-2}$ & $d_{i, t-3}$ & $d_{i, t-4}$ & $d_{i, t-5}$ \\
\hline $\begin{array}{l}\text { First Lagged Dependent Variable: } \\
\text { At Least Two Continuous Modal Donations }\end{array}$ & 1 & Base & $*$ & $*$ & $*$ & & & * & $*$ & $*$ \\
\hline $\begin{array}{l}\text { New Treatment } 1 \text { (Basement): } \\
\text { Two Continuous Modal Donations }\end{array}$ & 1 & Base & 0 & 0 & 0 & & 0 & $X$ & Y & $\mathrm{Z}$ \\
\hline $\begin{array}{l}\text { New Treatment 2: } \\
\text { Three Modal Donations }\end{array}$ & 1 & Base & 1 & 0 & 0 & & & \multicolumn{3}{|c|}{$\begin{array}{l}\text { Any one among the three } \\
\text { equals } \mathrm{n}-1 \text { donation amount. }\end{array}$} \\
\hline New Tretament 3: & 1 & Base & 0 & 1 & 0 & & & \multicolumn{3}{|c|}{$\begin{array}{l}\text { Any two among the three } \\
\text { equals } n-1 \text { donation amount. }\end{array}$} \\
\hline $\begin{array}{l}\text { New Treatment 4: } \\
\text { Five Continuous Modal Donations }\end{array}$ & 1 & Base & 0 & 0 & 1 & & & 0 & 0 & 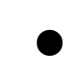 \\
\hline
\end{tabular}

Notes: The circular marks explain donations of an identical amount. X, Y, and Z explain donations that are different from the amount. The asterisk marks imply that the donation amount is not conditional. 
Table Appendix 1. Renewed model (2.2)

\begin{tabular}{|c|c|c|c|c|c|c|c|c|c|c|}
\hline Linear Probability Model & & & & & & (1) & $\begin{array}{l}\text { (2) } \\
\text { Fixed Fffects }\end{array}$ & (3) & (4) & $\begin{array}{l}\text { (5) } \\
\text { Half Panel Jackknife }\end{array}$ \\
\hline Model 2: The Five Most Recent Donations & n-1 & n-2 & n-3 & n-4 & n-5 & & & & & \\
\hline Lag1.Dependent Variable & $\bullet$ & $\bullet$ & * & * & * & $\begin{array}{l}0.044^{* *} \\
(0.018)\end{array}$ & $\begin{array}{c}0.019 \\
(0.018)\end{array}$ & $\begin{array}{l}0.071 * * * \\
(0.021)\end{array}$ & $\begin{array}{l}0.073 * * * \\
(0.021)\end{array}$ & $\begin{array}{l}0.039 * * \\
(0.019)\end{array}$ \\
\hline New Treatment 1 & - & ○ & $\mathrm{x}$ & $\mathrm{Y}$ & $\mathrm{Z}$ & Basement & Basement & Basement & Basement & Basement \\
\hline New Treatment 2 & ○ & - & \multicolumn{3}{|c|}{$\begin{array}{l}\text { Any one among three } \\
\text { equals } n-1 \text { donation. }\end{array}$} & $\begin{array}{l}0.100 * * * \\
(0.025)\end{array}$ & $\begin{array}{c}0.083^{* * * *} \\
(0.025)\end{array}$ & $\begin{array}{l}0.071^{* * *} \\
(0.029)\end{array}$ & $\begin{array}{c}0.071 * * * \\
(0.027)\end{array}$ & $\begin{array}{l}0.083^{* * * * *} \\
(0.025)\end{array}$ \\
\hline New Treatment 3 & ○ & ○ & \multicolumn{3}{|c|}{$\begin{array}{l}\text { Any two among three } \\
\text { equals n-1 donation. }\end{array}$} & $\begin{array}{l}0.190^{* * * * *} \\
(0.028)\end{array}$ & $\begin{array}{l}0.138 * * * \\
(0.027)\end{array}$ & $\begin{array}{l}0.150^{* * * * *} \\
(0.034)\end{array}$ & $\begin{array}{l}0.145 * * * \\
(0.034)\end{array}$ & $\begin{array}{c}0.149^{* * * *} \\
(0.027)\end{array}$ \\
\hline New Treatment 4 & ○ & $\bullet$ & $\bullet$ & $\bullet$ & $\bullet$ & $\begin{array}{l}0.351^{\text {****** }} \\
(0.039)\end{array}$ & $\begin{array}{l}0.247^{* * * *} \\
(0.036)\end{array}$ & $\begin{array}{l}0.294 * * * \\
(0.045)\end{array}$ & $\begin{array}{l}0.291 * * * \\
(0.045)\end{array}$ & $\begin{array}{c}0.280^{* * * * *} \\
(0.045)\end{array}$ \\
\hline Arellano-Bond test for AR(1), p-value & & & & & & - & - & 0.000 & 0.000 & - \\
\hline Arellano-Bond test for AR(2), p-value & & & & & & - & - & 0.107 & 0.109 & - \\
\hline Hansen test, p-value & & & & & & - & - & 0.080 & 0.214 & - \\
\hline (over-ID restrictions) & & & & & & - & - & $(22)$ & (29) & - \\
\hline N-1 th Donation Amount (Log-transformed) & & & & & & YES & YES & YES & YES & YES \\
\hline Number of Previous Donations & & & & & & YES & YES & YES & YES & YES \\
\hline Target Completion Rate & & & & & & YES & YES & YES & YES & YES \\
\hline From Inception of the Webpage & & & & & & YES & YES & YES & YES & YES \\
\hline FE Campaign Webpage & & & & & & NO & YES & YES & YES & YES \\
\hline FE Monthly & & & & & & YES & YES & YES & YES & YES \\
\hline FE Weekday & & & & & & YES & YES & YES & YES & YES \\
\hline FE Timezone & & & & & & YES & YES & YES & YES & YES \\
\hline
\end{tabular}

1. The number of donations is 9,989 , and the number of campaign webpages is 291 .

2. Cluster robust standard errors in parentheses $* * * \mathrm{p}<0.01, * * \mathrm{p}<0.05, * \mathrm{p}<0.1$.

3. The dependent variable is a binary variable, which takes 1 when $\mathrm{n}$ th donation amount is equal to $\mathrm{n}-1$ th donation amount.

4. The circular marks explain donations of an identical amount. X, Y, and Z explain donations that are different from the amount. The asterisk marks imply that the donation amount is not conditional. 


\section{References}

Agrawal, A.K., Catalini, C. and Goldfarb, A. (2013). Some simple economics of crowdfunding (No. w19133). National Bureau of Economic Research.

Andreoni, J. and Petrie, R. (2004). Public goods experiments without confidentiality: A glimpse into fund-raising. Journal of Public Economics, 88(7), 1605-1623.

Alpizar, F., Carlsson, F. and Johansson-Stenman, O. (2008). Anonymity, reciprocity, and conformity: Evidence from voluntary contributions to a national park in Costa Rica. Journal of Public Economics, 92(5), 1047-1060.

Arellano, M., and Bond, S. (1991). Some tests of specification for panel data: Monte Carlo evidence and an application to employment equations. The Review of Economic Studies, 58(2), 277-297.

Asch, S.E. (1951). Effects of group pressure upon the modification and distortion of judgments. Groups, leadership, and men, pp.222-236.

Asch, S.E. (1955). Opinions and social pressure. Scientific American, 193, 31-35.

Banerjee, A.V. (1992). A simple model of herd behavior. The Quarterly Journal of Economics, 107(3), 797-817.

Bazzi, S., and Clemens, M. A. (2013). Blunt instruments: avoiding common pitfalls in identifying the causes of economic growth. American Economic Journal: Macroeconomics, 5(2), 152-186.

The Behavioral Insights Team. (2013). Applying behavioural insights to charitable giving. Cabinet Office.

Bernheim, B.D. (1994). A theory of conformity. Journal of Political Economy, 102, 841877.

Bikhchandani, S., Hirshleifer, D. and Welch, I. (1992). A theory of fads, fashion, custom, and cultural change as informational cascades. Journal of Political Economy, 100(5), 992-1026.

Blake, T., Nosko, C. and Tadelis, S. (2014). Consumer heterogeneity and paid search effectiveness: A large scale field experiment (No. w20171). National Bureau of Economic Research.

Blundell, R., and Bond, S. (1998). Initial conditions and moment restrictions in dynamic panel data models. Journal of econometrics, 87(1), 115-143.

Bøg, M., Harmgart, H., Huck, S. and Jeffers, A.M. (2012). Fundraising on the Internet. Kyklos, 65(1), 18-30.

Bond, R. (2005). Group size and conformity. Group Processes \& Intergroup Relations 
8(4), 331-354.

Bun, M.J.G., Sarafidis, V., and Baltagi, B.H. (2015). Dynamic panel data models. The Oxford handbook of panel data, 76-110.

Bun, M.J.G, and Carree, M. A. (2005). Bias-corrected estimation in dynamic panel data models. Journal of Business and Economic Statistics, 23(2), 200-210.

Cialdini, R.B. (1993). Influence: science and practice. Harper Collins College.

Claidière, N., Bowler, M. and Whiten, A. (2012). Evidence for weak or linear conformity but not for hyper-conformity in an everyday social learning context. PloS one, 7(2), e30970.

Claidière, N., Bowler, M., Brookes, S., Brown, R. and Whiten, A. (2014). Frequency of behavior witnessed and conformity in an everyday social context. PloS one, 9(6), e99874.

Croson, R. and Shang, J. (2013). Limits of the effect of social information on the voluntary provision of public goods: evidence from field experiments. Economic Inquiry 51(1), 473-477.

Dhaene, G., and Jochmans, K. (2015). Split-panel jackknife estimation of fixed-effect models. The Review of Economic Studies, 82(3), 991-1030.

Frey, B.S. and Meier, S. (2004). Social comparisons and pro-social behavior: Testing 'conditional cooperation' in a field experiment. The American Economic Review, 94(5), 1717-1722.

Gerard, H.B., Wilhelmy, R.A. and Conolley, E.S. (1968). Conformity and group size. Journal of Personality and Social Psychology, 8, 79-82.

Hahn, J., and Kuersteiner, G. (2002). Asymptotically unbiased inference for a dynamic panel model with fixed effects when both $\mathrm{n}$ and $\mathrm{T}$ are large. Econometrica, 70(4), 1639-1657.

Hardwick, P. (2014). Characteristics of a good year-end fundraising letter. Mississippi Business Journal, Retrieved January 23, 2017 from http://msbusiness.com/2014/12/phil-hardwick-characteristics-good-year-endfundraising-letter/.

Hospido, L. (2012). Modelling heterogeneity and dynamics in the volatility of individual wages. Journal of Applied Econometrics, 27(3), 386-414.

Hospido, L. (2015). Wage dynamics in the presence of unobserved individual and job heterogeneity. Labour Economics, 33, 81-93.

Japan Fundraising Association. (2012). GivingJapan 2012. Tokyo: Keidanren Publishing. Johnson, G.A., Lewis, R.A. and Reiley, D. (2014). Location, location, location: repetition 
and proximity increase advertising effectiveness. Available at SSRN 2268215.

Jones, D. and Linardi, S. (2014). Wallflowers: Experimental evidence of an aversion to standing out. Management Science, 60(7), 1757-1771.

Kiviet, J.F. (1995). On bias, inconsistency, and efficiency of various estimators in dynamic panel data models. Journal of Econometrics, 68(1), 53-78.

Lewis, R.A. and Reiley, D.H. (2014). Online ads and offline sales: measuring the effect of retail advertising via a controlled experiment on Yahoo! Quantitative Marketing and Economics, 1-32.

Martin, R. and Randal, J. (2008). How is donation behavior affected by the donations of others? Journal of Economic Behavior and Organization, 67(1), 228-238.

Messick, D.M. (1999). Alternative logics for decision making in social settings. Journal of Economic behavior and Organization, 39(1), 11-28.

Nickell, S. (1981). Biases in Dynamic Models with Fixed Effects. Econometrica, 49(6), 1417-26.

Prior, A. (2014). How Charities Can Get More Out of Donors: What the Latest Research Says About Getting People to Give. The Wall Street Journal, Retrieved January 23, 2017 from http://www.wsj.com/articles/how-charities-can-get-more-out-ofdonors-1418598068.

Rege, M. and Telle, K. (2004). The impact of social approval and framing on cooperation in public good situations. Journal of Public Economics 88(7), 1625-1644.

Roodman, D. (2009a). A note on the theme of too many instruments. Oxford Bulletin of Economics and statistics, 71(1), 135-158.

Roodman, D. (2009b). How to do xtabond2: An introduction to difference and system GMM in Stata. Stata Journal, 9(1), 86-136.

Rosenberg, L. (1961). Group size, prior experience, and conformity. The Journal of Abnormal and Social Psychology, 63(2), 436.

Samek, A.S. and Sheremeta, R.M. (2014). Recognizing contributors: An experiment on public goods. Experimental Economics, 17(4), 673-690.

Sasaki, S. (2014). An Exact Conformity of Online Donors. Journal of Behavioral Economics and Finance, Vol.7, Proceedings of the $8^{\text {th }}$ Annual Meeting, 88-91.

Sasaki, S. (2015). Conformity in Charitable Giving: Evidence from Empirical Analysis of Japanese Online Donations. Science of Philanthropy Initiative (SPI) Working Paper, 139, 1-37.

Shang, J. and Croson, R. (2009). A field experiment in charitable contribution: The impact of social information on the voluntary provision of public goods. The Economic 
Journal, 119(540), 1422-1439.

Shang, J., Reed, A. and Croson, R. (2008). 'I' give but 'we' give more: the impact of identity and the mere information effect on donation behavior. Journal of Marketing Research, 45, 351-61.

Smith, S., Windmeijer, F. and Wright, E. (2015). Peer effects in charitable giving: evidence from the (running) field. The Economic Journal, 125(585), 1053-1071.

Tanford, S. and Penrod, S. (1984). Social Influence Model: A formal integration of research on majority and minority influence processes. Psychological Bulletin, 95(2), 189-225.

Zafar, B. (2011). An experimental investigation of why individuals conform. European Economic Review, 55(6), 774-798. 